\title{
The Composition in the Cognitive Theory of the Text (Based on J.K. Rowling's Tales)
}

\author{
Dr. Elena Solodova \\ Sevastopol State University 14-б Kesaev Str., apt.9, Sevastopol 299038 \\ The Russian Federation
}

\begin{abstract}
The research of the composition of the tale's text is conducted within the linguistic and cognitive approach. The composition of the text of tales is viewed as the linguistic and cognitive construal. Emphasize is laid on three aspects of the composition: compositional plot, compositional meaning and verbal one.
\end{abstract}

Keywords: composition, the cognitive poetics, the conceptual analysis, the linguistic and cognitive construal.

\section{I.INTRODUCTION}

Linguistic and cognitive research of the composition of the artistic text has originated in the depth of historical, structural and semantic poetics long before the scientific legalization of cognitive linguistics as a paradigm of knowledge. However, the study of composition in linguistic and cognitive aspect assumes not only the use of achievements of the previous scientific paradigms but the developments of the new ones, in particular, the division of the composition into outer and inner one.

Together with the formation of cognitive paradigm of knowledge (4) the linguistic research did not lose the unitarian view on the language and its nature since the statements about overall material essence of language stay unchanging $[16$, p. 20]. This fact gives reason to analyze with special attention the elaborations in which not only the outer (graphical) layer of the composition of the text is studied but the attempts to comprehend the directions of human thinking in the process of understanding of this layer are made. As part of the linguistic and cognitive approach to the research of composition the focus of attention is shifted towards the revealing and analysis of the cognitive mechanisms of structuring the knowledge about the world. The impulse to activate them is the specific composition of lingual forms objectified in the verbal layer of the composition of the text $[19$, p. 322].

The understanding quite progressive for its time of the composition of the artistic text as a construal of conscience belongs to Propp: "The composition does not exist in reality as there are no general notions in the world of things: they exist only in human conscience. However by means of general notions we perceive the world, discover its laws and learn to manage them" [18, p. 220]. Compare: "The basis of the compositional plot structure of the text is mental model since it represents its reference" [22, p. 237].

The backgrounds of the linguistic and cognitive approach to the determination of the composition are traced in the works of Lotman who proposed that there is some coding system between the living situations and "lyric situations" of the poetic text, which defines how these or that phenomena from the world of reality are reflected in the construction of the text. One of the basic coding systems of such type is the structure of the artistic thinking [15, p. 89; see also 11, p. 16].

In the works devoted to the linguistic and cognitive analysis of the text of tales an attempt was made to reconstruct the compositional structures of its content. So, for instance, in the thesis of Eremeeva the compositional structure of the content of the English folk tales is proposed in which the generalized images of characters (similar to those marked by Propp) are presented as the subjects of the propositional structures provided by the static (qualitative) and dynamic (functional) attributes [7, p. 48]. The conceptual basis of each generalized image of the character of tale is presented in the form of subject and centric frame where in the conceptual space of the character the predicate zones of attributes, functions, motivations and results of actions are included [7, p.48-52]. The typical structures of the conceptual space of each actant endued in the tale by specific role (the categorical type of the character) are united in the result into common conceptual model. However, it is marked that in the text of the real tale not the whole model is presented but the part of it. Such parts correspond to the types of conceptual models of different tales. In their total these models create prototypical category that has its center and periphery [7, p. 109-121, 193]. Within the framework of our research the composition of the tale is viewed as the model in which the characters, their functions, attributes, motivations and the results of actions coexist in a single system.

The idea of modeling the information proposed by Eremeeva in the context of our research has got its further development in the modeling of the semantic space of the tale, revealing the model of its content. 
Using the conception of the basic frames, stated in the works of Zhabotinskaya [see $8 ; 9 ; 10]$, for reconstruction of the compositional models structuring the content of the poetic text, allowed Spivak to singularize six basic schemes of the development of the poetic text. These schemes are in fact compositional meaning structures underlaying the artistic and poetic competence of author and reader. The conceptual schemes of the compositional meaning structure correlates with the generalized model of the compositional meaning structure of the poetic text, which reflects the compositional peculiarities of the poetic speech attributed also to other artistic texts and tales in particular [21].

As a part of the cognitive area quite productive appeared to be the approach to the research of the text as space $[1 ; 3 ; 6 ; 17]$. In the categories of space the text is considered not only as assembly of signs in-line but also the assembly of senses [2, p. 51]. The space of any text is at least double-pole: it contains the field of signs (sign-oriented bodies) and semantic field [20, p. 38]. Apart from the text space where its constitute lingual units are arranged in the specific sequence there is another space which is truly semantic [17, p. 36]. At that, two types of such space are distinguished - virtual and actual [17, p. 36]. The virtual space is specified by selection of content-related units in the process of text generation and realized by the mechanism of intention. The actual semantic space - is a space where the result of comprehension and understanding of the text in whole is formed [17, p. 36].

Under the influence of new paradigm of knowledge, the cognitive linguistic, the representation of semantic organization of the artistic text has essentially changed and enriched. From the new positions the decomposition of the semantic text in the categories of content and sense is viewed.

In terms of the cognitive linguistic the content is formed as mental formation modeling the fragment of the artistic reality presented in the text whilst the meaning is the thought about this reality, i. e. the interpretation of what is reported in the text [2, p. 123]. The content is based on the denotative (referential) structures reflecting the objective "state of things" in the world, real and imaginary. The meaning is based on the units of other nature connected with instinctive knowledge [17, p. 37]. In other words, the meaning is connected with the process of conceptualization, i. e. the understanding of things, phenomena and events of the real and imaginary worlds. The conclusion can be made that the content of the text correlates with its denotative and referential basis whereas the meaning - with interpretational component of the semantic space, with its conceptual orientation. It appears, in its turn, that the denotative and referential component of the mental space is explicated in the text while the meaning is mainly extracted from it. The extraction of meaning is realized via the analysis of both the semantic and conceptual spaces of the text. The conceptual space represents the mental space arising in the consciousness of the reader upon reading the artistic text. This space includes the generalized content and prime text meanings [2, p. 58-59]. The conceptual analysis is the method of explication of the conceptual area of the artistic text based on the semantic analysis of assembly of those linguistic units which reveals a theme or microtheme of the area under research [2, p. 58; 13, p. 3].

Within the framework of our research the conceptual analysis of the modern author's tale focuses on revealing of its meaning via extracting of text concepts, metaphorical and metonymical conceptual schemes actualized in the semantics of the text. The conceptual analysis has much in common with the traditional semantic analysis of the linguistic units. However, the semantic analysis is oriented on revealing of the linguistic meaning and forms of its realization as the assembly of denotative, significative and connotative components of meaning while the conceptual analysis - is a search of those concepts, i.e. structural units of thinking to which the body of sign is "laid on" $[12$, p. 85 ; see also 5, p. $121 ; 10$, p. 2]. The conceptual analysis is directed more on the study of knowledge organization of the world, presented in the semantics of the linguistic unit, than on explanation of this unit $[8 ; 10]$. In our research the text of author's tale is considered as sign.

In the cognitive poetics, oriented on the explanation of the mechanisms of creative activity, the composition of the text draws absolutely new presentation and construed as linguistic and cognitive construal which exists in the artistic and poetic consciousness of specific historical and cultural community. This construal provides the formation of the text and conditions the type of its compositional meaning structure [21, p. 22].

In our research while considering the composition of the text as linguistic and cognitive construal the special emphasis is laid on the revealing of three aspects of composition: the compositional plot structure, compositional meaning structure and verbal one. At that, the compositional plot structure of the text of tale is the structure of its content, i. e. the information, which is presented in the text. Compositional meaning structure is connected with the interpretation of the content of the text. The verbalization of these structures is performed by different formal means enabling the adequate inference of the meaning of the text. 


\section{REFERENCES}

[1]. Aleksandrova, O. V. (2001). The Space of the Text. The categorization of the world: spaceand time: Moscow.: pp. $15-25$.

[2]. Babenko, L. G., Kazarin U.V. (2004). The Linguistic Analysis of the Artistic Text. Flinta, Nauka: Moscow.

[3]. Bart, R. (1980). The Textual Analysis. New in the Foreign Linguistics, 9: 307312.

[4]. Belekhova, L. I. (2005). The Modern Linguistics in Ukraine and Worldwide: Scientific Paradigms, Preliminary Studies, and Perspectives. The Scientific Bulletin of Kherson State University, II: 8 - 15.

[5]. Belekhova, L. I. (2004). Image Space of American Poetry: Cognitive Perspective. Zvezdopad: Kherson.

[6]. Dibrova, E. I. (2001). The Space of the Text. The Categorization of the World: Space and Time: Moscow.: pp. $34-36$.

[7]. Eremeeva, N.F. (1997). Conceptual Space of the English Folk Tales. ChNU: Cherkassy.

[8]. Jabotinskaya, S. A. (1999). Conceptual Analysis: types of frames. The Bulletin of Cherkassy University, 11: $12-25$

[9]. Jabotinskaya, S. A. (2000). Conceptual Model of Part of Speech Systems: frame and script. Cognitive Aspects of Linguistic Categorization: $15-21$.

[10]. Jabotinskaya, S. A. (2004). Conceptual Analysis of Language: Frame Nets. Problems of Applied Linguistics, 9: $81-92$.

[11]. Krasnykh, V.V. (2003). "A Friend" Among "Foes": Myth or reality. Gnozis: Moscow.

[12]. Kubryakova, E. S. (1991). About One Fragment of Conceptual Analysis of the Word MEMORY. Logical Analysis of Language. Cultural Concepts. Nauka: Moscow.

[13]. Kubryakova, E. S. (1994). Inceptive Stages of Cognitivizm: Linguistics - Psychology - Cognitive Science. Problems of Linguistics, 4: $3-14$.

[14]. Lotman, U.M. (1992). Culture and Explosion. Genesis: Moscow.

[15]. Lotman, U.M. (1996). About Poets and Poetry. Iscusstvo-SPB: Saint Petersburg.

[16]. Manakin, V.N. (2004). Comparative Lexicology. Znaniya: Kyiv.

[17]. Novikov, A.I. (2001). Semantic Space of Text and Ways of Its Division. Categorization of the World: Space and Time. Dialog: Moscow.

[18]. Propp, V.Y. (1969). The Morphology of the Folk Tale. Eastern Literature: Moscow.

[19]. Rastorguyeva, G.V. (2005). In the Search of the Truth In the Message "About Another Person's Intellectual Effort": The Poetical Text. TSU: Tambov.

[20]. Sorokin, U. A. (2001). Text and Its Space. Categorization of the World: Space and Time. Dialog: Moscow.

[21]. Spivak, S. M. (2004). Proper Names In Compositional Meaning Structure of Poetic Texts of American Poetry: Communicative And Cognitive Approach. Kyiv.

[22]. Tomashevsky, B.V. (1959). The Verse and Language: The Philological Sketches. Gosizdat: Moscow. 